\title{
Examining the Effects of Women's Body Image and Body Satisfaction on Self-Esteem, Happiness, and Body Satisfaction
}

\author{
Camille B. Pearce \\ Janelle R. McDaniel, PhD \\ Seth Tackett \\ University of Louisiana at Monroe \\ College of Business \& Social Sciences \\ Department of Psychology \\ 700 University Avenue \\ Monroe, Louisiana 71209 \\ United States \\ Krista L. Nelson, PhD, LPC \\ Southern Arkansas University \\ Behavioral \& Social Sciences \\ Department of Psychology \\ 100 East Universities, MSC 9293 \\ Magnolia, AR 71753 \\ United States
}

\begin{abstract}
This study investigated the effects of positive versus negative self-talk on self-esteem, happiness, and body satisfaction levels, and the effects of viewing images of overweight and thin women on these variables. In the first study, female participants $(N=79)$ were randomly assigned to one of four groups. Each group was asked to complete a specific task, which was describing either positive or negative attributes about their own body and/or physical appearance or own personality. In the second study, female participants $(N=99)$ were randomly assigned to one of three groups. The first group viewed images of overweight women. The second group viewed images of thin women. The third group viewed images of women's smiling faces, with no photos of the body. Significant positive and negative correlations were found possibly indicating society lacks recognition that females are at risk for negative self-beliefs relating directly back to personal body-esteem.
\end{abstract}

Self-esteem, body image, eating disorders, physical appearance

Examining the Effects of Women's Body Image and Body Satisfaction on

Self-Esteem, Happiness, and Body Satisfaction

\section{Introduction}

There are multitudes of research studies which have identified correlations between body image and self-esteem. Past investigations have focused on personal body image dissatisfaction and its relationship with self-esteem in college students (Pop, 2016; Axelsson \& Langdon, 2017; Lim \& You, 2017; ; Lowery et al., 2005; Baba \& Sugawara, 2000; Olivardia, Pope, Borowiecki, \& Cohane, 2004) and also in adolescence (Bell \& Dittmar, 2011; Gitau, Micklesfield, Pettifor, \& Norris, 2014; Hutchinson, Rapee, \& Taylor, 2010; Gatti, Ionio, Traficante, \& Confalonieri, 2014). Bedford and Johnson (2006) examined body image in older women. Examination of body image satisfaction has even been studied in elementary aged children (Shin \& Shin, 2008; Smolak, 2004; Phares, Steinberg, \& Thompson, 2004; Frost \& McKelvie, 2004).

There are many factors, particularly for females, that influence body imageincluding culturalideals, norms in society, physical changes in our bodies, and behavioral occurrences (Bedford \& Johnson, 2006). One of the most common influences of being dissatisfied with our personal bodies stems from being aware of what is viewed as norms for attractiveness and flawlessness by society and our personal cohort of friends, colleagues, and contemporaries (Myers \& Crowther, 2009). Since our society and media regularly expound on the significance of body mass and body shape, it is not surprising that beliefs about the need to restrict food intake are widespread and readily adopted within our Western society (Veazey Morris, Parra, \& Stender, 2011). 
The changing social and technological environment in our world has been impactful on our levels of personal body satisfaction. Past studies have determined that one of the most influential factors on the development of body image dissatisfaction is the media (Thompson \& Stice, 2001; Bedford \& Johnson, 2006; Heinberg, 1996), particularly how we internalize the media ideal for body images and compare those images to ourselves (Rodgers, McLean, $\&$ Paxton, 2015). Media communication, regarding the thin-ideal, are inordinately powerful and have been identified as negatively impacting body esteem in media audiences (Hohlstein, Smith, \& Atlas, 1998). The thin-ideal internalization, which is the belief that "thin is good," occurs when significant or important and respected individuals, oftentimes parents, peers, or the media, express that thinner is better (Thompson \& Stice, 2001). Media in Western cultures have been criticized for the creation of a body standard, or body ideal, which is unrealistic for most women to achieve (Strahan et al., 2008). The concept of a "thin-ideal" in the media is portrayed as a desirable and beautiful woman who is uncharacteristically thin (Lacroix, 2004). Since the 1980s, researchers have argued that societal and cultural norms impact body dissatisfaction in women (Rodin, Silberstein, \& Striegel-Moore, 1985). The sociocultural norms established for what is the ideal appearance are most intended for women and are widespread and extensive. The norms established express to women that they are valuable because of their physical appearance and physical bodies. These norms further communicate that beauty standards are high for what is considered to be attractive, and women should compare themselves and attempt to achieve these ideal standards for beauty (Rodin et al., 1985). Younger women have been found to be influenced more by media and the thin ideal than are women who are older in age, which is likely attributable to a higher pervasiveness of media in the lives of younger women (Bedford \& Johnson, 2006).

Disturbing to comprehend is the knowledge that women are accepting of these thin-ideal standards that are being projected onto them by the media. The concept of conformity to public demand has been identified as concern for appropriateness (CFA), which regarding the concept of body image would include compliance with imposed pressure from society to attain an ideal body (Lennox \& Wolfe, 1984; Bedford \& Johnson, 2006). Because the ideal body is typically unattainable for most women, the individual may be "faced with attitude-behavior discrepancy" (Bedford \& Johnson, 2006, p. 43) that can generate the development of body image dissatisfaction. Therefore, CFA as a paradigm has been identified as an important possible correlation between culture and our perceptions of body image (Bedford \& Johnson, 2006).

Unfortunately, our "ideal" body standards, which are established by the media, are learned early. By early adolescence, girls are cognizant of the established model of what the media considers to be the ideal body standard (Spurr, Berry, \& Walker, 2013).Girls in preschool have been noted as having a partiality for thinner body types (Tremblay, Lovsin, Zecevic, \& Lariviere, 2011) and are mindful that it is undesirable to be overweight as women. Smolak and Murnen (2011) found preschoolers already perceived it is important for women to be pretty. Girls as young as 10-years old have begun dieting behaviors (Pliner, Chaiken, \& Flett, 1990). Further, research identified girls as young as 5-years old disclosing fears of gaining weight and having unhealthy body esteem (Tremblay et al., 2011). The media is impactful on young women, particularly adolescent girls, because it influences them to base their feelings of self-worth from their physical appearance (Spurr et al., 2013).

Body image has been defined as "the internal representation of your own outer appearance- your own unique perception of yourself" (Thompson, Heinberg, Altabe, \& Tantleff-Dunn, 1999, p. 4). Body image is subjective and is based on self-observation about one's physical appearance as well as the reactions from other individuals (Spurr et al., 2013). It has been hypothesized as displaying multidimensional beliefs regarding one's own body (Mendelson, Mendelson, \& White, 2001) and is an indispensable component of our self-identity and self-concept (Hurd, 2000; Chrisler \& Ghiz, 1993).Thompson (1996) and Cash and Pruzinsky (1990) theorize that body image is related directly to one's self-beliefs about their own physique dimensions, form, and aesthetics. The feelings that an individual has regarding their weight has been argued to be different than their personal feelings regarding their general appearance (Mendelson, White, \& Mendelson, 1996).

The concept of body image dissatisfaction (BID) occurs when there is a discrepancy or contradictionin an individual's existingbody image and their ideal body image (Cash \& Strachan, 1999).Unfortunately, past research has identified that most women from North American are unhappy with their bodies (Hurd, 2000; Garner, 1997; Berscheid, Walster, \& Bohrnstedt, 1973). One study identified that for girls, the physical aspects of self, including weight and appearance, are significantly influential on personal self-esteem levels, which suggests that body satisfaction and self-esteem levels are high correlated constructs (Gatti et al., 2014).

Over the past 30 years, body image dissatisfaction has significantly increased in women (Thompson et al., 1999). Since 1972, women who are dissatisfied with their bodies has increased from 23 to 56 percent (Thompson et al., 1999).The sociocultural emphasis on being thin in current society, particularly in America, has been identified as significant in the growth and continuation of unhealthy eating habits and low body esteem (Stice \& Shaw, 1994; Esteban, 2003; Paxton, Schutz, Wertheim, \& Muir, 1999; Halmi, 1994). There are numerous influences which can contribute to personal body dissatisfaction in a young woman (Balcetis, Cole, Chelberg, \& Alicke, 2013). 
Past studies have identified that references to body weight from family or friends, often done by teasing or weightrelated comments, or family suggestions to begin dieting, are impactful on female levels of body dissatisfaction (Fulkerson et al., 2002; Keery, Eisenberg, Boutelle, Neumark-Sztainer, \& Story, 2006).

Within the United States, body dissatisfaction has been identified as a predictor for abnormal eating patterns in young females (Rosen, 1990; Cattarin \& Thompson, 1994; Mildred, Paxton, \& Wertheim, 1995). Disordered eating (DE) can be categorized as a range of thoughts, feelings, and behaviors related to the fixation on personal body mass, food restraint and limitation, and restriction of foodstuff (Torstveit, Rosenvinge, \& Sundgot-Borgen, 2007). The disordered eating can also include such behaviors as binge eating, inducing the self to vomit, and the use of diuretics, laxatives and diet pills as means to ensure that weight gain does not occur. Disordered eating is linked to extensive personal body dissatisfaction. Individuals who display disordered eating do so in an attempt to achieve their desired body weight (Torstveit et. al, 2007). Unfortunately, there is some linkage between some individuals displaying disordered eating and also displaying abnormal body image concerns (Cowden, 2017).

Eating disorders have been identified, after obesity and asthmas, as the third most widespread recurring illness in teenage girls (Golden et al., 2003). According to ANRED, more than half of teen girls are currently dieting, or believe they should be dieting (ANRED; Anorexia Nervosa \& Related Eating Disorders, 2018). Anorexia nervosa prevalence for teen girls is approximately 1 percent; while bulimia nervosa affects about 4 percent of college-age females (ANRED, 2018).Body dissatisfaction has been identified for decades (Strober \& Yager, 1989) as a contributing factor to the increase in eating disorders, particularly on college campuses and havinglow self-esteem feelings (Mendelson, McLauren, Gauvin, \& Steiger, 2002; Mable, Balance, \& Galgan, 1986). Studies have established that women who have eating disorders are likely to display significantly less personal self-esteem than their non-eating disordered counterparts (Mendelson et al., 2002; Rudd \& Lennon, 2000). Having low self-esteem was identified as a risk factor for displaying body image issues and disturbances in eating habits (Paxton et al., 1999), while weight fluctuations were hypothesized as creating unstable levels of self-esteem (Striegal-Moore, McAvay, \& Rodin, 1986). One study postulated that the primary influence on the development of eating disorders is the struggle with self-evaluation regarding body weight and body shape, its impact on personal self-esteem, which results in restriction of food intake (Pike, Loeb, \& Vitousek, 2000).

The current study sought to explore the effects of positive versus negative self-talk on self-esteem, happiness, and personal levels of body satisfaction. This experiment hypothesized that the women participants who were asked to write about positive self-attribute would show higher ratings of happiness, self-esteem, and body satisfaction levels. Contrastingly, it was hypothesized that the women participants who are asked to write about negative selfattributes, would result in lower ratings of happiness, self-esteem, and personal body satisfaction levels.

\section{Method}

\subsection{Study One}

\subsubsection{Participants}

Participants in this study were 79 female undergraduate students enrolled in undergraduate psychology classes at the University of Louisiana at Monroe. In terms of university classifications, 59.5\% were freshmen, $32.9 \%$ were sophomores, $2.5 \%$ were juniors, and $5.1 \%$ were seniors. Of the participants, $100 \%$ of them were female. Age of the participants ranged from 16 to 53 with a mean of 19.46 and a standard deviation of 4.190.

\subsubsection{Materials}

\subsubsection{Consent form}

The consent form provided to the participants prior to the beginning of the study contained all of the study procedures and contact information that is required to reach the principal investigator or the experimenter. Participants were asked to sign this document and return it to the researcher. This document will be kept in the experimenter's records for the duration of time indicated by the American Psychological Association's (APA) research guidelines.

\subsubsection{Demographics questionnaire}

The demographics questionnaire utilized in this study consisted of a series of items designed to gather general participant's demographic information, which included gender, age, sex, and ACT or SAT scores. Participants were instructed that these items do require a response, but all answers are confidential and will be aggregately reported.

\subsubsection{Stunkard Silhouette Scale (Stunkard, 1983)}

The Stunkard Silhouette Scale consists of ten images of women of varying sizes, usually from small to large. The participant was asked to pick a photo that accurately depicts what size they think they are, what size they feel they are, and what size they want to be. 


\subsubsection{Rosenberg Self-Esteem Scale (Rosenberg, 2015)}

The Rosenberg Self-Esteem scale is a 10-item instrument that is used to assess self-esteem. Each item is completed by choosing one of the 4-point Likert scale measures, which range from strongly agree to strongly disagree. The scores are kept on a continuous scale, and higher scores indicate higher levels of self-esteem.

\subsubsection{Subjective Happiness Scale (Lyubomirsky, \& Lepper, 1999)}

This four-item scale measures subjective happiness. Each item is completed by choosing one of the 7-items that finish a provided sentence fragment prompt. The options are different for each of the four questions, such as "In general, I consider myself..." that is followed by a 7-point Likert scale that ranges from "not a very happy person" to "a very happy person". Scores are kept on a continuous scale and summed up at the end. Higher scores indicated higher levels of subjective happiness.

\subsubsection{Ben-Tovim Walker Body Attitude Questionnaire (Ben-Tovim, \& Walker 1991)}

This 44-item scale is designed to assess a broad range of attitudes that women hold regarding their bodies. The participant is given a statement such as, "I usually feel physically attractive" and are asked to rate it on a 5-point Likert scale. The scores are divided by subscales including Attractiveness, Disparagement, Feeling Fat, Salience, Lower Body Fitness, and Strength/Fitness. Measurement scores are kept on a continuous scale; higher scores indicate higher levels of individual subscales.

\subsubsection{Procedure}

The study was approved by the University of Louisiana at Monroe's Institutional Review Board. Each participant was randomly assigned to a group, which determined the prompt that the individual would obtain in their questionnaire packet. Participants in Group 1 were asked to describe positive attributes of their own body and/or physical appearance. Participants in Group 2 were asked to describe positive attributes of their own personality. Participants in Group 3 were asked to describe negative attributes of their own body and/or physical appearance. Participants in Group 4 were asked to describe negative attributes of their own personality. All participants were asked to sign a consent form agreeing to participate in the research study. Additionally, all participants were asked to complete a brief demographics form, followed by their assigned questionnaire packet. At the end of each session, questionnaire packets were collected and stored in the principal investigators office and kept the required amount of time designate by the APA.

\subsection{Study Two}

\subsubsection{Participants}

Participants included 99 undergraduate female students from the University of Louisiana at Monroe. In terms of university classifications, $61.6 \%$ were freshmen, $27.3 \%$ were sophomore, $7.1 \%$ were juniors, and $4 \%$ were seniors. Age of the participants ranged from 18 to 53 with a mean of 19.72 and a standard deviation of 4.29.

\subsubsection{Materials}

\subsubsection{Consent form}

A consent form was provided to the participants prior to the beginning of the study. Within the consent form, information regarding the study procedures and contact information for the principal investigator was provided. Participants were asked to sign the consent form document and return it to the researcher. These documents will be kept in the principal investigator's records for the duration of time as indicated by APA.

\subsubsection{Demographics questionnaire}

The demographics questionnaire utilized in this study consisted of a series of items designed to gather general demographic information about each participant, which included gender, age, sex, and ACT or SAT scores. Participants were instructed to fully complete the demographics information, but all answers are to remain confidential and will not be separately reported. Instead, research data will be aggregately summarized.

\subsubsection{Stunkard Silhouette Scale (Stunkard, 1983)}

The Stunkard Silhouette Scale consists of ten images of women of varying sizes, which typically ranges from small to large. Each participant is asked to pick which image that accurately depicts what size they think they are, what size they feel they are, and what size they want to be.

\subsubsection{Rosenberg Self-Esteem Scale (Rosenberg, 2015)}

The Rosenberg Self-Esteem scale is a 10-item scale created to assess self-esteem. The scale consists of a 4-point Likert-type scale measure ranges from strongly agree to strongly disagree. The scores are kept on a continuous scale with higher scores indicating higher levels of personal self-esteem. 8 


\subsubsection{Subjective Happiness Scale (Lyubomirsky, \& Lepper, 1999)}

This four-item scale assesses subjective happiness. Each scale item is completed by choosing one of the 7-items that finish a given sentence fragment. The options are different for each of the four questions, such as "In general, I consider myself..." which is followed by a 7-point Likert scale with ranges from "not a very happy person" to "a very happy person". Scores are kept on a continuous scale to be summed up at the end. Higher scores are indications of higher levels of subjective happiness.

\subsubsection{Ben-Tovim Walker Body Attitude Questionnaire (Ben-Tovim, \& Walker 1991)}

This 44-item scale is designed to assess a broad range of attitudes that women hold towards their own personal bodies. Each participant is given a statement such as "I usually feel physically attractive" and asked to rate that statement on a 5-point Likert scale. The scores are divided by subscales such as Attractiveness, Disparagement, Feeling Fat, Salience, Lower Body Fitness, and Strength/Fitness. The scores are kept on a continuous scale with higher scores being indicative of higher levels of individual subscales.

\subsubsection{Procedure}

The study was approved by the University of Louisiana at Monroe's Institutional Review Board. Each participant was randomly assigned to a group, which determined the images the individual viewed at the beginning of the session. Participants in Group 1 viewed images of overweight women. Participants in Group 2 viewed images of thin women. Participants in Group 3 viewed images of women's faces that were smiling, but they did not view any photos of the model woman's body. All participants were asked to sign a consent form at the beginning of the study session. Next, participants were asked to complete the brief demographics form, which was followed by their individualized questionnaire packet. At the end of each session, questionnaire packets were collected to be stored in the principal investigator's office for the requisite amount of time designated by the APA.

\section{Results}

\subsection{Study One}

\subsubsection{Correlations}

Significant positive correlations existed between the happiness and self-esteem scales $(r=.62)$, BAQ's feelings of fatness and BAQ's salience subscales $(r=.66)$, BAQ's feelings of attractiveness subscale and self-esteem scale $(r=$ .65). For the Silhouette scale, a difference score was calculated for the ratings of "how you 'think' you look" and "how you 'want' to look" to measure how far away actual self is from ideal self. We referred to this as Silhouette difference. We found significant positive correlations with the Silhouette difference and the BAQ scale $(r=.59)$, the BAQ's feeling of fatness subscale ( $r=.63$ ), and BAQ's disparagement subscale $(r=.60)$.

Significant negative correlations were found between the BAQ scale and self-esteem scale $(r=-.56)$, BAQ's feelings of fatness subscale and self-esteem scale $(r=-.61)$, and BAQ's disparagement subscale and self-esteem $(r=$ $-.69)$.

\subsubsection{Ratio of Emotions to Thoughts}

Individual responses were reviewed by outside reviews along with associate researchers to develop an emotional indicator. The emotional indicator includes 2 primary positive emotions (Love, and Joy), 1 primary neutral emotion (Surprise), and 3 primary negative emotions (Anger, Sadness, and Fear). Using the above emotional indicator, certain words and phrases were used to divide each prompt into either a positive, negative, or neutral category (Figures $1 \& 2$ ). 


\section{Figure 1: Correlations of the Frequency of Emotions Among Females}

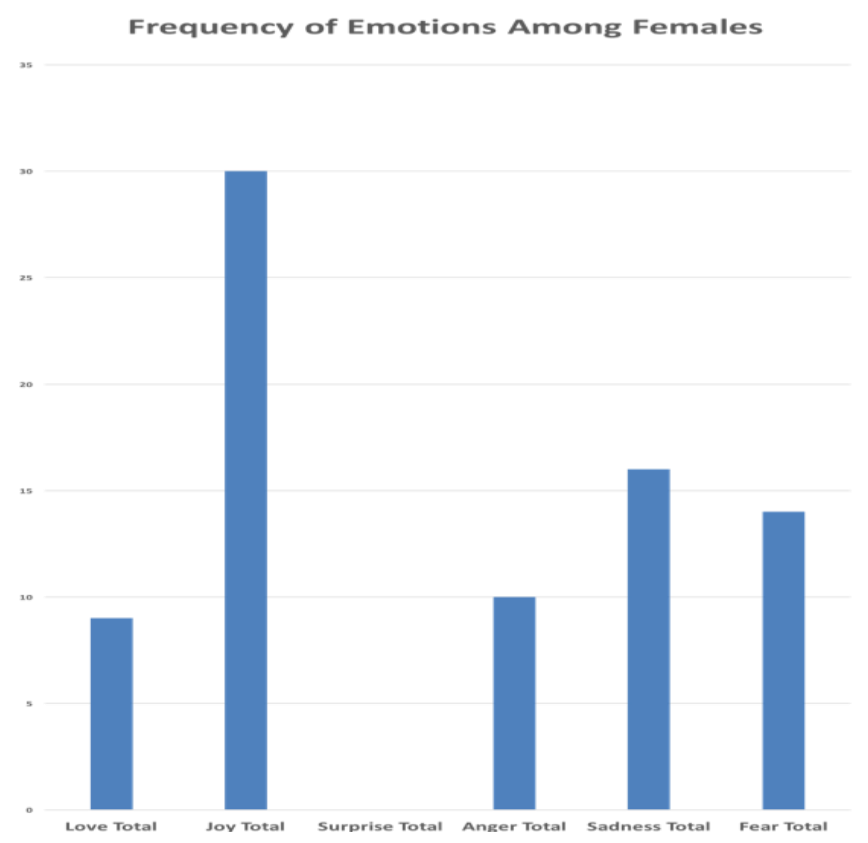

Figure 2: Correlations of Emotions Shown Among Conditions

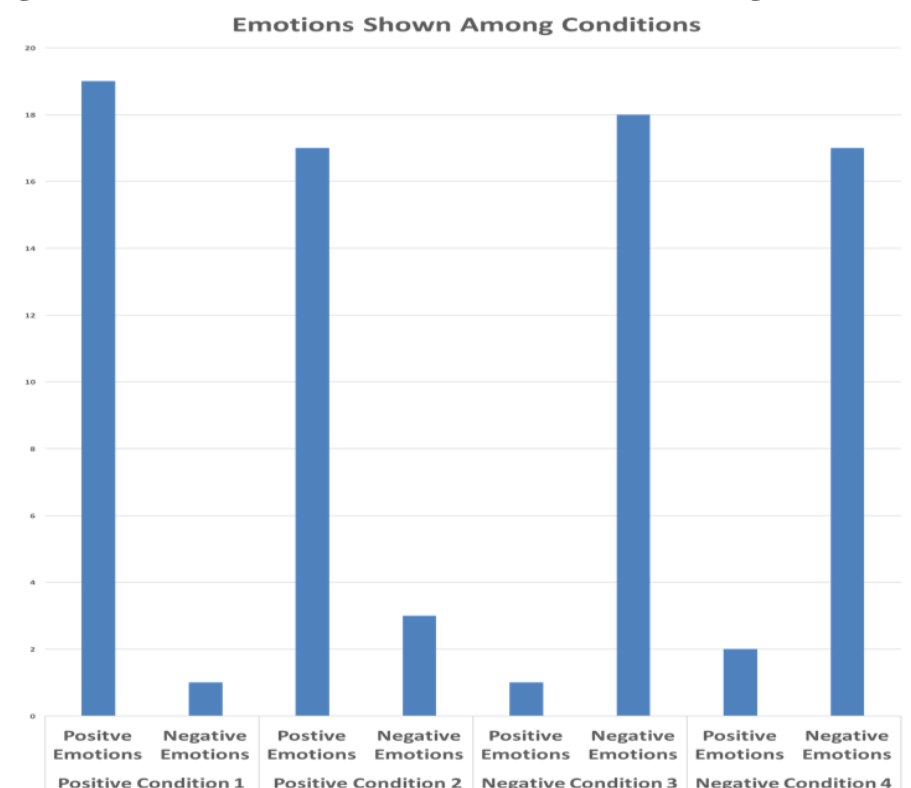

\subsection{Study Two}

\subsubsection{Correlations}

A significant positive correlation was found between self-esteem and BAQ attractiveness $(r=.744)$ as well as selfesteem and happiness $(r=.615)$. A significant negative correlation was found between self-esteem and BAQ disparagement ( $r=-.748)$, self-esteem and BAQ feelings of fatness ( $r=-.685)$, self-esteem and total BAQ $(r=-.624)$, and self-esteem and BAQ salience $(r=-.634)$. Turning to the Silhouette scale, we found a significant positive correlation between scale difference and BAQ feelings of fatness $(r=.701)$ as well as scale difference and total $\mathrm{BAQ}(r=.685)$.

A significant positive correlation was found between scale difference and BAQ disparagement ( $r=.562$ ), happiness and BAQ attractiveness $(r=.408)$, scale difference and BAQ lower body $(r=.404)$, scale difference and BAQ salience $(r=.530)$, and self-esteem and BAQ strength $(r=.422)$. A significant negative correlation was found between self-esteem and BAQ lower body $(r=-.397)$, happiness and BAQ salience $(r=-.450)$, self-esteem and scale difference $(r=-.521)$, happiness and scale difference $(r=-.358)$, and happiness and BAQ total $(r=-.391)$. 


\section{Discussion}

\subsection{Study One}

Daily, women are faced with societal inoculation of current standards of ideal body shape and image (Rodgers et al, 2015). The present research aimed to identify how positive and negative self-talk can impact individual happiness, levels of personal self-esteem, and subjective body satisfaction. This study examined the variables of self-esteem, perceived self-body image, and beliefs about individualized personality attributes that contribute to happiness levels in women. Results indicate that overall, women who feel anxiety regarding their personal body image are less likely to experience the levels of happiness that are evident in women who do not experience concern about body image. Dissatisfaction with body type correlates with reduced happiness levels.

Positive correlations were noted between the variables of self-esteem and happiness. Specifically, this finding indicates that as self-esteem increases, there is an increase in reported feelings of happiness as well. The results indicate that there is a significant relationship to feeling happy and feeling good about the self. A positive relationship was noted also that when women feel attractive, their self-esteem increases. The results support the idea that women feel better about themselves when they feel that they are physically attractive.

The perception of feeling fat subscale and the salience subscale of the BAQ were also positively correlated. This relationship indicates that as women experience the perception that they are fat, they are also judging their bodies because they believe that weight and shape of their body is important. Therefore, if a women is experiencing feelings that they are overweight, they are also judging that their body and/or weight is undesirable.

The Silhouette instrument is a means for examining how similar, or dissimilar, the ideal self is when compared to the actual self. The "Silhouette difference score" demonstrated relationships between the body attitudes and the actual versus ideal self. First, a positive correlation was noted between the Silhouette difference score and the BAQ. Noting that the BAQ is an instrument that examines how women feel about their bodies, this correlation suggests that how women feel about their bodies is impacted by how they perceive their actual self when comparing themselves to their ideal self. For example, if a women feels there is a large discrepancy between her actual self and her ideal self, then the likelihood is that she will have stronger negative feelings about her body. Conversely, if a woman believes there are minimal differences between her actual self and ideal self, she will have stronger positive feelings regarding her body.

Another notable positive correlation was identified between the Silhouette difference and the BAQ feeling of fatness subscale. This information indicates that as women experience differences in their actual versus ideal selves, the likelihood is that they are also experiencing feelings of being overweight or "fat." The Silhouette difference was also found to correlate with the BAQ disparagement scale. This relationship shows that as women experience disparity between their actual self and their ideal self, they are also feeling derision, or even possibly self-disgust, with their bodies.

Self-esteem was identified as being negatively correlated with the BAQ and with the BAQ subscales, feelings of fatness and disparagement. The BAQ, which is a means for women to be assessed about how they feel about their bodies, can demonstrate that poor body attitudes can have a negative impact on how women feel about themselves. Particularly, women seem to display lower self-esteem as they identify self-attitudes about their individual body. Higher scores on the BAQ subscale, feelings of fatness, showed a significant relationship with self-esteem. Specifically, as women experience feelings of being overweight or fat, they display a significant reduction in selfesteem and how they feel about themselves. Finally, the BAQ disparagement subscale was noted to have a negative impact on self-esteem. As feelings of self-loathing were evident in higher numbers on the disparagement subscale, there was a notable decrease in reported self-esteem by women. This indicates that when women devalue themselves with disparaging remarks, they are thereby impacting their personal self-esteem levels in a negative manner.

\subsection{Study Two}

This study investigated the effects of viewing images of thin women, overweight women, and images of faces on self-esteem and mood variables. While there were no significant results found related to viewing the images, there were interrelationships of the other variables tested. As in Study 1, a significant positive relationship was identified between self-esteem and happiness. Self-esteem was also recognized to be positively correlated to the BAQ subscale of attractiveness. Self-esteem was negatively correlated with the BAQ subscales of feeling of fatness and disparagement. The BAQ subscale of salience displayed a negative relationship also with self-esteem. Notably, when women have an increase in how they view their body weight and shape, this often impacts how they feel about themselves, lowering their individual self-esteem.

The Silhouette scale difference provided several positive correlations. The first, the Silhouette scale difference between the actual self-versus the ideal self was found to correlate positively with the BAQ overall scale. 
This association means that as there is an increasing difference between the actual and ideal selves, the women tends to have increasingly strong feeling about herself. Next, the other noteworthy correlation is that between the Silhouette difference and the subscale of feelings of fatness. In other words, as there appears to be a discrepancy between actual versus ideal selves, there is a positive relationship with women who report that they also feel fat. They look at their ideal self and describe that they feel overweight.

The Silhouette scale was identified as being positively correlated with the BAQ subscale disparagement. This indicates that as there is scale difference between the actual and ideal selves, the woman is experiencing increasing feelings of disgust for her body. Silhouette scale difference and the BAQ subscale of consciousness of lower body fat were also positively correlated suggesting that as there is an increasing discrepancy between the actual versus ideal selves, then women are increasingly self-conscious that they have body fat on their lower body. The BAQ subscale of salience was identified as having a positive relationship with the Silhouette scale difference. This finding indicates that as the scale difference increases, there is also an increase in how women perceive the importance of body weight and body shape.

Self-esteem was identified as positively correlating with the BAQ subscale of strength. The strength subscale is a measure of how women perceive their own levels of physical strength and fitness. As women recognize their increasing levels of physical fitness and/or strength, the data indicates this positively impacts how they feel about themselves increasing their self-esteem. Happiness and the BAQ subscale of attractiveness were also positively correlated. These relationships indicate that happiness is higher when women feel they are physically attractive.

These results indicate that happiness is directly impacted by how women view their bodies. Additionally, women who are increasingly aware of having lower body fat appear to have diminished self-esteem. Women who believe that body weight and shape are important have lower levels of reported happiness. When there are increasing discrepancies between the ideal and the actual selves, self-esteem and personal levels of happiness are negatively impacted in a significant manner.

\subsection{Limitations}

Future research will need a larger population sample for data collection. While having no male participants could be construed as a study limitation, this research focused on the views and beliefs that women have about their own bodies and how those feelings impact happiness and self-esteem beliefs. Prospective future research could possibly incorporate the inclusion of males into the research investigation.

\subsection{Future Hopes}

The recognition that females are particularly at risk for negative self-beliefs that relate directly back to body esteem is apparent. Society must understand that women are exposed to daily suggestions about what is desirable for body weight and shape, and these exposures can prove detrimental to physical and mental health. Fortunately, research has identified that body positivity information can negate the negative impact of the media's body ideal. Strong messages of body acceptance and self-love, particularly to young women and adolescent girls, can assist in reducing the impact of societal norms expounding what is expected of females in terms of weight management and body shape. The key is education and communication to women and girls who are at risk for developing detrimental body esteem and poor body image.

\section{References}

ANRED - Anorexia Nervosa \& Related Eating Disorders (2018). As found on https://www.anred.com/stats.html on February 25, 2018).

Axelsson, I. M, \& Langdon, J. (2017). Comparison of self-esteem, body image, and motives of physical activity in college students in group and solo exercise(Master's thesis). Available from Georgia Southern University, University Honors Program Theses, 298.

Baba, A. \& Sugawara, K. (2000). Drive for thinness in adolescent women. Japanese Journal of Educational Psychology, 48, $267-274$.

Balcetis, E., Cole, S., Chelberg, M. B., \& Alicke, M. (2013). Searching out the ideal: Awareness of ideal body standardspredicts lower global self-esteem in women. Self \& Identity, 12, 99 - 113.

Bedford, J. L., \& Johnson, C. S. (2006). Societal influences on body image dissatisfaction in younger and older women. Journal of Women and Aging, 18, 41-55.

Bell, B. T., \& Dittmar, H. (2011). Does media type matter? The role of identification in adolescent girls' media consumption and the impact of different thin-ideal media on body image. Sex Roles, 65, $478-490$.

Ben-Tovim, D. I., \& Walker, M. K. (1991). The development of the Ben-Tovim Walker BodyAttitudes Questionnaire (BAQ), a new measure of women's attitudes towards their own bodies. Psychological medicine, 21(3), 775-784.

Berscheid, E., Walster, E., \& Bohrnstedt, G. (1973). Body image: The happy American body. A survey report. Psychology Today, 7, $119-131$. 
Cash, T. F., \& Pruzinsky, T. (Eds.). (1990). Body images: Development, deviance, and change. New York: Guilford Press.

Cash, T. F., \& Strachan, M. D. (1999). Body images, eating disorders, and beyond. In R. Lemberg (Ed.), Eating disorders: A reference sourcebook. (pp. 27 - 36). Phoenix, AZ: Oryx Press.

Cattarin, J., \& Thompson, J. K. (1994). A three year longitudinal study of body image and eating disturbances in adolescent females. Eating disorders: The Journal of Prevention and Treatment, 2, $114-125$.

Chrisler, J. C., \& Ghiz, L. (1993). Body image issues of older women. In N.D. Davis, E. Cole, and E. D. Rothblum (Eds.), Faces of women and aging. (pp. 67 - 75). New York, NY: Harrington Park.

Cowden, S. (2017). Body dysmorphic disorder and eating disorders. (As found on https://www.verywellmind.com/body-dysmorphic-disorder-eating-disorders-1138186 on February 25, 2018).

Esteban, C. M. (2003). The effects of media images on women's body esteem across ethnicity. Dissertation Abstracts International: Section B: The Sciences and Engineering, 63, 3911.

Frost, J., \& McKelvie, S. (2004). Self-esteem and body satisfaction in male and female elementary school, high school, and university students. Sex Roles, 51, 45 - 54.

Fulkerson, J. A., McGuire, M. T., Neumark-Sztainer, D., Story, M., French, S. A., \& Perry, C. L. (2002). Weightrelated attitudes and behaviors of adolescent boys and girls who are encouraged to diet by their mothers. International Journal of Obesity Related Metabolic Disorders, 26, 579 - 587.

Garner, D. M. (1997). The 1997 body image survey results. Psychology Today, 30, 30 - 44.

Gatti, E., Ionio, C., Traficante, D., \& Confalonieri, E. (2014). "I like my body: Therefore, I like myself": How body image influences self-esteem - A cross sectional study on Italian adolescents. Europe's Journal Of Psychology, 10, $301-317$.

Gitau, T. M., Micklesfield, L. K., Pettifor, J. M., \& Norris, S. A. (2014). Eating attitudes, body image satisfaction, and self-esteem of South African black and white male adolescents and their perception of female body silhouettes. Journal of Child and Adolescent Mental Health, 26, 193-205.

Golden, N. H., Katzman, D. K., Kreipe, R. E., Stevens, S. L., Sawyer, S. M.,\& Rees, J. (2003). Eating disorders in adolescents: Position paper of the Society of Adolescent Medicine. Journal of Adolescent Health, 33, 496 $-503$.

Halmi, K. A. (1994). A multimodal model for understanding and treating eating disorders. Journal of Women's Health, 3, $487-493$.

Heinberg, L. J. (1996). Theories of body image: Perceptual, developmental, and sociocultural factors. In J. K. Thompson (Ed.), Body image, eating disorders, and obesity: An integrative guide for assessment and treatment (pp. 27 - 48). Washington, DC: American Psychological Association.

Hohlstein, L. A., Smith, G. T., \& Atlas, J. G. (1998). An application of expectancy theory to eating disorders: Development and validation of measures of eating and dieting expectancies. Psychological Assessment, 10, $49-58$.

Hurd, L. C. (2000). Older women's body image and embodied experience: An exploration. Journal of Women and Aging, 12, 77 - 97.

Hutchinson, D. M., Rapee, R. M., \& Taylor, A. (2010). Body dissatisfaction and eating disturbances in early adolescence: A structural modeling investigation examining negative affect and peer factors. The Journal of Early Adolescence, 30, 489 - 517.

Keery, H., Eisenberg, M. E., Boutelle, K., Neumark-Sztainer, D., \& Story, M. (2006). Relationships between maternal and adolescent weight-related behaviors and concerns: The role of perception. Journal of Psychosomatic Research, 61, 105-111.

Lacroix, C. (2004). Images of animated others: The orientalization of Disney's cartoon heroines from The Little Mermaid to The Hunchback of Notre Dame. Popular Communication, 2,

$213-229$.

Lennox, R. D., \& Wolfe, R. N. (1984). Revision of the self-monitoring scale. Journal of Personality and Social Psychology, 46, $1349-1364$.

Lim, S. A., \& You, S. (2017). Effects of self-esteem and depression on abnormal eating behavior among Korean female college students: Mediating role of body dissatisfaction. Journal of Child and Family Studies, 26, 176-182.

Lowery, S. E., Robinson Kurpius, S. E., Befort, C., Hull Blanks, E., Sollenberger, S., Foley

Nicpon, M., \& Huser, L. (2005). Body image, self-esteem, and health-related behaviors among male and female first year college students. Journal of College Student Development, 46, 612-623.

Lyubomirsky, S., \& Lepper, H. S. (1999). A measure of subjective happiness: Preliminary reliability and construct validation. Social indicators research, 46(2), 137-155.

Mable, H. M., Balance, W. D., \& Galgan, R. J. (1986). Body image distortion and dissatisfaction in university students. Perceptual \& Motor Skills, 63, $907-911$. 
Mendelson, B. K., McLauren, L., Gauvin, L., \& Steiger, H. (2002). The relationship of self- esteem and body esteem in women with and without eating disorders. International Journal of Eating Disorders, 31, 318 324.

Mendelson, B. K., Mendelson, M. J., \&White, D. R. (2001). Body esteem scale for adolescents and adults. Journal of Personality Assessment, 76, $90-106$.

Mendelson, B. K., White, D. R., \& Mendelson, M. J. (1996). Self-esteem and body esteem: Effects of sex, age, and weight. Journal of Applied Developmental Psychology, 17, 321 - 346.

Mildred, H., Paxton, S. J., \& Wertheim, E. H. (1995). Risk factors for eating disorders in Greek- and AngloAustralian adolescent girls. International Journal of Eating Disorders, 17, 91 - 96.

Myers, T. A., \& Crowther, J. H. (2009). Social comparison as a predictor of body satisfaction: A meta-analytic review. Journal of Abnormal Psychology, 4, 683 - 698.

Olivardia, R., Pope, Jr., H. G., Borowiecki III, J. J., Cohane, G. H. (2004). Biceps and body image: The relationship between muscularity and self-esteem, depression, and eating disorder symptoms. Psychology of Men \& Masculinity, 5, 112-120.

Paxton, S. J., Schutz, H. K., Wertheim, E. H., \& Muir, S. L. (1999). Friendship clique and peer influences on body image concerns, dietary restraint, extreme weight-loss behaviors, and binge eating in adolescent girls. Journal of Abnormal Psychology, 108, $255-266$.

Phares, V., Steinberg, A. R., \& Thompson, J. K. (2004). Gender differences in peer and parental influences: Body image disturbance, self-worth, and psychological functioning in preadolescent children. Journal of Youth and Adolescence, 33, 421-429.

Pike, K. M., Loeb, K., \& Vitousek, K. (2000). Cognitive-behavioral therapy for anorexia nervosa and bulimia nervosa. In J.K. Thompson (Ed.), Body image, eating disorders, and obesity: An integrative guide for assessment and treatment (pp. 253 - 302). Washington, DC: American Psychological Association.

Pliner, P., Chaiken, S., \& Flett, G. (1990). Gender differences in concern with body weight and physical appearance over the life span. Personality and Social Psychology Bulletin, 16, 263 - 273.

Pop, C. (2016). Self-esteem and body image perception in a sample of university students. Eurasian Journal of Educational Research, 64, 31-44.

Rodgers, R. F., McLean, S., \& Paxton, S. J. (2015). Longitudinal relationships among internalization of the media ideal, peer social comparison, and body dissatisfaction: Implications for the Tripartite influence model. Developmental Psychology, 51, $706-713$.

Rodin, J., Silberstein, L., \& Striegal-Moore, R. (1985). Women and weight: A normative discontent. In T. B. Sonderegger (Ed.), Nebraska Symposium on Motivation (Vol. 32, 267 - 307.) Lincoln: University of Nebraska Press.

Rosen, J. C. (1990). Body-image disturbance in eating disorders. (In T. E. Cash \& T. Pruzinsky (Eds.), Body Images: Development, deviance, and change.) New York: The Guilford Press.

Rosenberg, M. (2015). Society and the adolescent self-image. Princeton university press.

Rudd, N. A., \& Lennon, S. J. (2000). Body image and appearance-management behaviors in college women. Clothing \& Textiles Research Journal, 18, $152-162$.

Shin, N. Y., \& Shin, M. S. (2008). Body dissatisfaction, self-esteem, and depression in obese Korean children. The Journal of Pediatrics, 152, 502-506.

Smolak, L. (2004). Body image in children and adolescents: Where do we go from here? Body Image, 1, 15-28.

Smolak, L., \& Murnen, S. K. (2011). The sexualization of girls and women as a primary antecedent of selfobjectification. In R. M. Calogero, S. Tantleff-Dunn, \& J. Thompson

(Eds.), Self-objectificationin women: Causes, consequences, and counteractions (pp. 53 -75). Washington, DC: American Psychological Association.

Spurr, S., Berry, L., \& Walker, K. (2013). Exploring adolescent views of body image: the influence of media. Issues In Comprehensive Pediatric Nursing, 36, 17 - 36.

Stice, E., \& Shaw, H. E. (1994). Adverse effects on the media-portrayed thin ideal on women and linkages to bulimic symptomatology. Journal of Social Clinical Psychology, 13, 288 - 308.

Strahan, E. J., Lafrance, A., Wilson, A. E., Ethier, N., Spencer, S. J., \& Zanna, M. P. (2008). Victoria's dirty secret: How sociocultural norms influence adolescent girls and women. Personality and Social Psychology Bulletin, 34, 288 - 301.

Striegel-Moore, R., McAvay, G., \& Rodin, J. (1986). Psychological and behavioral correlates of feeling fat in women. International Journal of Eating Disorders, 5, 935 - 947.

Strober, M., \& Yager, J. (1989). Some perspectives on the diagnosis of bulimia nervosa. Journal of College Student Psychotherapy, 3, $3-12$.

Stunkard, A. J. (1983). Use of the Danish adoption resister for the study of obesity and thinness. Genetics of neurological and psychiatric disorders.

Thompson, J. K. (1996). Body image, eating disorders, and obesity: An integrative guide for assessment and treatment. (Ed.). Washington, DC: American Psychological Association. 
Thompson, J. K., Heinberg, L. J., Altabe, M. A., and Tantleff-Dunn, S. (1999). Exacting Beauty: Theory, assessment, and treatment of body image disturbance. Washington, DC: American Psychological Association.

Thompson, J. K., \& Stice, E. (2001). Thin-ideal internalization: Mounting evidence for a new Riskfactor for bodyimage disturbance and eating pathology. Current Directions in Psychological Science, 10, 181 - 183.

Torstveit, M. K., Rosenvinge, J. H., \& Sundgot-Borgen, J. (2007). Prevalence of eating disorders And the predictive power of risk models in female elite athletes: A controlled study. Scandinavian Journal of Medicine \& Science in Sports, $1-11$.

Tremblay, L., Lovsin, T., Zecevic, C., \& Lariviere, M. (2011). Perceptions of self in 3-5 year old children: A preliminary investigation into the early emergence of body dissatisfaction. Body Esteem, 8, 287-292.

Veazey Morris, K. D., Parra, G. R., \& Stender, S. R. (2011). Eating attitudes and behaviors among female college students. Journal of College Counseling, 14, 21 - 33. 